\title{
Acute Cytotoxic and Vasogenic Edema after Subarachnoid Hemorrhage: A Quantitative MRI Study
}

\author{
(D).M. Weimer, (DS.E. Jones, and (DJ.A. Frontera
}

\begin{abstract}
BACKGROUND AND PURPOSE: The mechanism of early brain injury following subarachnoid hemorrhage is not well understood. We aimed to evaluate if cytotoxic and vasogenic edema are contributing factors.
\end{abstract}

MATERIALS AND METHODS: A retrospective analysis was conducted in patients with SAH undergoing diffusion-weighted MR imaging within 72 hours of onset. Apparent diffusion coefficient values derived from DWI were evaluated by using whole-brain histograms and 19 prespecified ROIs in patients with SAH and controls with normal findings on MRI. Cytotoxic edema observed outside the ROIs was assessed in patients with SAH. The average median ADC values were compared between patients with SAH and controls and patients with SAH with mild (Hunt and Hess 1-3) versus severe early brain injury (Hunt and Hess 4-5).

RESULTS: We enrolled 33 patients with SAH and 66 controls. The overall average median whole-brain ADC was greater for patients with $\mathrm{SAH}\left(808 \times 10^{-6} \mathrm{~mm}^{2} / \mathrm{s}\right)$ compared with controls $\left(788 \times 10^{-6} \mathrm{~mm}^{2} / \mathrm{s}, P<.001\right)$ and was higher in patients with SAH across ROIs after adjusting for age: cerebral gray matter ( 826 versus $\left.803 \times 10^{-6} \mathrm{~mm}^{2} / \mathrm{s}, P=.059\right)$, cerebral white matter $\left(793\right.$ versus $758 \times 10^{-6} \mathrm{~mm}^{2} / \mathrm{s}, P=$ .023), white matter tracts (797 versus $\left.739 \times 10^{-6} \mathrm{~mm}^{2} / \mathrm{s}, P<.001\right)$, and deep gray matter $\left(754\right.$ versus $\left.713 \times 10^{-6} \mathrm{~mm}^{2} / \mathrm{s}, P=.016\right)$. ADC values trended higher in patients with Hunt and Hess $4-5$ versus those with Hunt and Hess 1-3. Early cytotoxic edema was observed in 13 (39\%) patients with SAH and was more prevalent in those with severe early brain injury (87.5\% of patients with Hunt and Hess $4-5$ versus $24.0 \%$ of those with Hunt and Hess $1-3, P=.001)$.

CONCLUSIONS: Age-adjusted ADC values were globally increased in patients with SAH compared with controls, even in normalappearing brain regions, suggesting diffuse vasogenic edema. Cytotoxic edema was also present in patients with SAH and correlated with more severe early brain injury.

ABBREVIATIONS: $\mathrm{EBI}=$ early brain injury; $\mathrm{HH}=$ Hunt and Hess

E

arly brain injury (EBI) incurred during aneurysm rupture in spontaneous subarachnoid hemorrhage is a major predictor of poor functional outcome, ${ }^{1,2}$ yet the mechanism for EBI is not well-understood. In both animal and human models, SAH leads to transiently elevated intracranial pressure with concomitant inadequate cerebral blood flow and, in severe cases, intracranial circulatory arrest. $^{3,4}$ This transient global hypoperfusion is associated with endothelial activation, microthrombosis, ischemia, and vasogenic

Received October 5, 2016; accepted after revision December 15.

From the Cerebrovascular Center of the Neurological Institute (J.M.W., J.A.F.) and the Imaging Institute (S.E.J.), Cleveland Clinic, Cleveland, Ohio.

This work was supported, in part, by the American Heart Association Student Scholarship in Cerebrovascular Disease and Stroke.

Please address correspondence to Jennifer A. Frontera, MD, FNCS, Cleveland Clinic Foundation, Cerebrovascular Center, 9500 Euclid Ave, S80, Cleveland, OH 44195; e-mail: frontej@ccf.org

Indicates article with supplemental on-line photo.

http://dx.doi.org/10.3174/ajnr.A5181 edema in animal models. ${ }^{5-7}$ As a part of routine clinical MR imaging at many institutions, diffusion-weighted imaging presents a unique opportunity for the study of patients with SAH in the acute period. Apparent diffusion coefficient values may serve as a practical and useful biomarker for the severity of EBI following SAH. In humans, we and others have demonstrated that MR imaging-detected infarctions on DWI occur acutely after SAH and before the onset of delayed cerebral ischemia/vasospasm. ${ }^{8-11}$

These infarctions are more common in patients with more severe EBI (Hunt and Hess [HH] 4-5); occur in unusual, nonvascular patterns (eg, corpus callosum, bilateral medial frontal lobes); and are associated with an increased risk of delayed cerebral ischemia and worse 3-month functional outcomes. ${ }^{8-10}$ The volume of infarction associated with worse functional outcomes is small, however. ${ }^{8}$ Thus, this finding led us to hypothesize that conventional, nonquantitative MR imaging techniques are not sensitive enough to detect the full extent of brain injury. 
We hypothesized that patients with SAH (compared with controls) would demonstrate global reductions in apparent diffusion coefficient values, indicating diffuse cytotoxic edema presumably due to ischemia/hypoperfusion, when whole-brain ADC mapping and ROI quantitative analyses were applied. We further hypothesized that patients with SAH with evidence of severe EBI would have a greater burden of cytotoxic edema than those with mild EBI.

\section{MATERIALS AND METHODS}

\section{Subject Enrollment and Data Collection}

A retrospective review of prospectively enrolled patients with spontaneous SAH was conducted between February 2013 and March 2015 as part of the Intracranial Hemorrhage ICU Project of Cleveland Clinic and Early Status of Coagulation, Platelet Activation and Outcome after Subarachnoid Hemorrhage (Principal Investigator, J.A.F.). ${ }^{1}$ As part of these studies, all eligible patients admitted to the neurologic intensive care unit within 72 hours of the onset of SAH symptoms were approached for enrollment. Inclusion criteria were being 18 years of age or older; $\mathrm{SAH}$ diagnosed by CT, MR imaging, or lumbar puncture; consent to participate in 3- and 12-month follow-up interviews; and DWI performed within 72 hours of ictus, before the clinical or radiographic onset of delayed cerebral ischemia/cerebral vasospasm (which typically occurs 3-14 days after aneurysm rupture). Exclusion criteria included SAH due to nonaneurysmal causes such as trauma, arteriovenous malformation, dural arteriovenous fistula, cavernous malformation, vasculitis, or arterial dissection. The severity of EBI due to SAH was assessed at admission by using the Hunt and Hess scale ${ }^{12}$ and was dichotomized as mild ( $\left.\mathrm{HH} 1-3\right)$ versus severe ( $\mathrm{HH} 4-5)$.

The control group was identified from a population of consecutive patients undergoing brain DWI on the same 1.5T inpatient scanners and were matched to patients with $\mathrm{SAH}$ in a 2:1 ratio. Records were queried from the hospital electronic record on inpatients 40-60 years of age (because this is the typical age range of patients with spontaneous SAH) undergoing brain MR imaging between January 2010 and December 2013 (the most recent time frame in which control data were available). Radiologists' image reports were reviewed to identify patients with normal findings on MRI and no evidence of intracranial pathology. Images were then independently reviewed by 2 reviewers (J.A.F., J.M.W.) to confirm the absence of intracranial pathology. Basic and demographic data were collected for both patients with $\mathrm{SAH}$ and controls. Admission clinical and radiographic data were also recorded for patients with SAH. This study was approved by our institutional review board.

\section{MR Imaging Postprocessing and Analysis}

All MRIs were performed on the same $1.5 \mathrm{~T}$ whole-body scanners (Magnetom; Siemens, Erlangen, Germany), and diffusionweighted images were obtained by using a standard single-shot, spin-echo, echo-planar sequence with b-values of $0 \mathrm{~mm}^{2} / \mathrm{s}$ and $1000 \mathrm{~mm}^{2} / \mathrm{s}$. ADC images were automatically generated from diffusion-weighted sequences ( $b=0$ and $b=1000$ series) following acquisition. To confirm their accuracy, ADC images were also reconstructed off-line by using Matlab R2013 software (Math-
Works, Natick, Massachusetts). Because differences between the scanner-generated and off-line-reconstructed images were negligible, representing $<1 \%$ of the maximal ADC signal, automatically generated ADC images were used for subsequent analyses.

Brain extractions were next performed on scans of all controls and patients with SAH with the FSL Brain Extraction Tool (http://fsl.fmrib.ox.ac.uk/fsl/fslwiki/BET), ${ }^{13}$ available through FSL (http://www.fmrib.ox.ac.uk/fsl; 2015) as part of the Mango image viewing software package (http://ric.uthscsa.edu/mango; 2015). Floor and ceiling threshold filters were applied to limit the images to voxel intensities between 250 and $1250 \times 10^{-6} \mathrm{~mm}^{2} / \mathrm{s}$ to restrict contributions from any remaining nonparenchymal signal, such as from the extra-axial or subarachnoid space (thereby excluding blood products in the subarachnoid space and intraventricular blood). The median whole-brain ADC was calculated for each subject. Whole-brain histograms with bin widths of $10 \times 10^{-6} \mathrm{~mm}^{2} / \mathrm{s}$ were generated. Histograms were normalized to account for variations in brain volume among patients, and histogram peaks were calculated. Smooth curves were fit to model the histograms by applying a moving average low-pass filter. Median ADC values were compared for both patients with SAH versus control subjects and those with mild EBI (Hunt and Hess 1-3) versus severe EBI (Hunt and Hess 4-5) as performed elsewhere. ${ }^{11}$

Traditional regional spatial profile analysis was also performed by using standardized volumetric software in a manner similar to that previously described. ${ }^{14}$ Images were loaded into the Medical Image Processing, Analysis, and Visualization software package (National Institutes of Health, Bethesda, Maryland; 2014), and symmetric ROIs were placed bilaterally over 19 predefined normal-appearing regions: gray matter of the frontal, parietal, occipital, and temporal lobes; white matter of the frontal, parietal, occipital, and temporal lobes; internal capsule, genu, and splenium of the corpus callosum; caudate head, lentiform nucleus, and thalamus; midbrain; hippocampus; pons; cerebellar nuclei; and white matter (On-line Figure). ${ }^{14}$ Median ADC values were reported for each subject ROI due to the possibility of individual voxel outliers within an individual ROI. Conclusions were unchanged if mean ADC values were used during ROI analysis and therefore were not reported. Average median ADC intensity was calculated for the following ROI combinations: cerebral gray matter (frontal, parietal, occipital, and temporal); cerebral white matter (frontal, parietal, occipital, and temporal); white matter tracts (genu, splenium, and internal capsule); deep gray matter (thalamus, caudate, and lentiform nucleus); and summed ROIs (all 19 regions). Hyperintense FLAIR signal related to remote lesions (eg, old stroke) or transependymal periventricular edema was excluded from ROI analysis. Ischemic lesions were not included in summed ROI comparisons and are reported separately as their own ROI group.

For patients with SAH, DWI and ADC images were also reviewed for evidence of cytotoxic edema outside prespecified ROIs, defined qualitatively as DWI hyperintense/ADC hypointense lesions. Cytotoxic edema lesions were manually traced to calculate total volume. Procedural-related lesions, such as those along known external ventricular drain tracts or craniotomy tra- 
Table 1: Summary of admission, demographic, clinical, and radiographic characteristics of patients with $\mathrm{SAH}^{\mathrm{a}}$

\begin{tabular}{|c|c|c|c|}
\hline & $\begin{array}{l}\text { Patients with } \\
\text { SAH }(n=33)\end{array}$ & $\begin{array}{l}\text { Controls } \\
(n=66)\end{array}$ & $\begin{array}{c}P \\
\text { Value }\end{array}$ \\
\hline \multicolumn{4}{|l|}{ Basic and demographic data } \\
\hline Age (yr) & $59(44.5-66)$ & $49(43.4-53.2)$ & $<.001^{\mathrm{b}}$ \\
\hline Female sex & $16(48.5 \%)$ & $41(62.1 \%)$ & .196 \\
\hline \multicolumn{4}{|l|}{ Race } \\
\hline Caucasian & $25(75.8 \%)$ & $47(72.3 \%)$ & .343 \\
\hline Black & $8(24.3 \%)$ & $14(21.5 \%)$ & \\
\hline Other & 0 & $4(6.2 \%)$ & \\
\hline History of smoking & $21(63.6 \%)$ & $34(51.5 \%)$ & .253 \\
\hline History of alcohol abuse & $7(22.6 \%)$ & $10(15.2 \%)$ & .370 \\
\hline Hypertension & $14(45.2 \%)$ & $33(50.0 \%)$ & .657 \\
\hline Diabetes & $4(12.9 \%)$ & $14(21.2 \%)$ & .326 \\
\hline Hyperlipidemia & $12(38.7 \%)$ & $24(36.4 \%)$ & .824 \\
\hline Aspirin use & $10(31.3 \%)$ & $22(33.3 \%)$ & .837 \\
\hline History of ischemic stroke & $1(3.0 \%)$ & 0 & - \\
\hline History of intracranial hemorrhage & 0 & 0 & - \\
\hline History of head trauma & 0 & 0 & - \\
\hline History of brain tumor & 0 & 0 & - \\
\hline Family history of aneurysm & $4(13.3 \%)$ & 0 & - \\
\hline Cocaine use within $24 \mathrm{hr}$ of ictus & $1(3.0 \%)$ & 0 & - \\
\hline \multicolumn{4}{|l|}{ Admission clinical and radiographic data } \\
\hline Premorbid modified Rankin Scale score 29 & $0(0-0)$ & & \\
\hline \multicolumn{4}{|l|}{$\mathrm{HH}$ grade $^{12}$} \\
\hline 1 & $5(15.2 \%)$ & & \\
\hline 2 & $14(42.4 \%)$ & & \\
\hline 3 & $6(18.2 \%)$ & & \\
\hline 4 & $5(15.2 \%)$ & & \\
\hline 5 & $3(9.1 \%)$ & & \\
\hline Glasgow Coma Score & $15(11.5-15)$ & & \\
\hline APACHE II score 30 & $7(3-10)$ & & \\
\hline \multicolumn{4}{|l|}{ Modified Fisher grade ${ }^{15}$} \\
\hline 1 & $4(12.1 \%)$ & & \\
\hline 2 & $2(6.1 \%)$ & & \\
\hline 3 & $18(54.5 \%)$ & & \\
\hline 4 & $9(27.3 \%)$ & & \\
\hline Hijdra sum score ${ }^{31}$ & $13.5(6-21)$ & & \\
\hline Cerebral edema on admission CT & $8(25.0 \%)$ & & \\
\hline External ventricular drain placed & $14(42.4 \%)$ & & \\
\hline
\end{tabular}

Note:-APACHE II indicates Acute Physiology and Chronic Health Evaluation II.

${ }^{a}$ Values are reported as No. (\%) or median (interquartile range). Comparative basic and demographic data are provided for controls.

b Statistical significance.

jectories, and lesions due to the presence of blood products were manually excluded from analysis.

\section{Statistical Plan}

Statistical analyses were performed by using the JMP 9.0 software package (SAS Institute, Cary, North Carolina; 2010). Univariate comparisons between patients with SAH and controls and between patients with SAH with severe $(\mathrm{HH} 4-5)$ versus mild $(\mathrm{HH}$ 1-3) EBI were performed by using the $\chi^{2}$ test for categoric variables and the Wilcoxon rank sum test for continuous variables. Multisample comparisons were performed with the Kruskal-Wallis test. For average median ADC comparisons between patients with SAH and controls with whole-brain and combined ROI measurements (cerebral white matter, cerebral gray matter, white matter tracts, deep gray matter, and summed ROIs), multivariable logistic regression models adjusted for patient age were also performed because there were significant age differences between patients with SAH and controls. Correlations between ADC values and age, the modified Fisher score, the presence of elevated intracranial pressure, and external ventricular drainage were evaluated by using 2-sided Spearman correlation coefficients.

\section{RESULTS}

During the study period, 33 patients with SAH underwent MR imaging within 72 hours of ictus and 66 controls 40-60 years of age with normalappearing MR imaging were evaluated. The most common indications for MR imaging in the control group were headache, altered mental status, weakness, and vertigo/dizziness/syncope. Basic and demographic data for patients with SAH and controls and SAH admission data are summarized in Table 1 . The median age of patients with SAH (59 years; interquartile range, 44.5-66 years) was significantly older than that in the control cohort (49 years; interquartile range, 43.4-53.2; $P<.001)$. There were no other significant baseline differences, including sex, race, history of smoking, history of alcohol abuse, hypertension, diabetes, hyperlipidemia, or aspirin use. Eight patients with SAH (24.2\%) had severe EBI (HH 4-5) on admission. Most patients with SAH had either modified Fisher grade 3 ( $n=18,54.5 \%$ ) or modified Fisher grade 4 bleeds $(n=9$, $27.3 \%){ }^{15}$

The average median whole-brain ADC value was significantly higher for the SAH cohort $\left(808 \times 10^{-6} \mathrm{~mm}^{2} / \mathrm{s}\right)$ compared with the control cohort $\left(788 \times 10^{-6} \mathrm{~mm}^{2} / \mathrm{s}, P<.001\right)$. Similarly, whole-brain histograms were right-shifted toward higher ADC values in the SAH cohort compared with controls (Fig 1). The peak of the averaged SAH histogram was located at the bin centered at $780 \times 10^{-6} \mathrm{~mm}^{2} / \mathrm{s}$, while the peak of the averaged control histogram was located at the bin centered at $750 \times 10^{-6} \mathrm{~mm}^{2} / \mathrm{s}$.

Average median ADC values for ROIs in patients with $\mathrm{SAH}$ and controls are reported in Table 2. Across all ROIs, the average median ADC was higher in the SAH cohort compared with the control group $\left(795 \times 10^{-6} \mathrm{~mm}^{2} / \mathrm{s}\right.$ for patients with $\mathrm{SAH}$ versus $759 \times 10^{-6} \mathrm{~mm}^{2} / \mathrm{s}$ for controls, $\left.P<.001\right)$. The greatest differences were observed in the white matter tracts and the cerebral white matter of the brain, along with deep gray matter structures, while differences among gray matter ROIs were smaller.

When we compared patients with $\mathrm{SAH}$ with mild EBI $(\mathrm{HH}$ 1-3) versus severe EBI ( $\mathrm{HH} 4-5)$, the average median wholebrain ADC values were similar between groups $\left(808 \times 10^{-6}\right.$ $\mathrm{mm}^{2} / \mathrm{s}$ for HH $1-3$ versus $811 \times 10^{-6} \mathrm{~mm}^{2} / \mathrm{s}$ for $\mathrm{HH} 4-5, P=$ .514). However, the histogram peak for those with mild EBI 
was centered at $780 \times 10^{-6} \mathrm{~mm}^{2} / \mathrm{s}$, while the histogram peak for those with severe EBI was centered at $800 \times 10^{-6} \mathrm{~mm}^{2} / \mathrm{s}$, resulting in the distributions shown in Fig 2. Across most individual ROIs, the average median ADC intensity was greater in patients with SAH with severe EBI compared with those with mild EBI (Table 3), though the results were not statistically significant. Similarly, there was no significant difference in average median ADC values for summed areas of cerebral gray matter $(P=.159)$, cerebral white matter $(P=.147)$, deep gray matter $(P=.074)$, white matter tracts $(P=.916)$, and total summed ROIs $(P=.200)$ between patients with SAH with mild-versus-severe EBI.

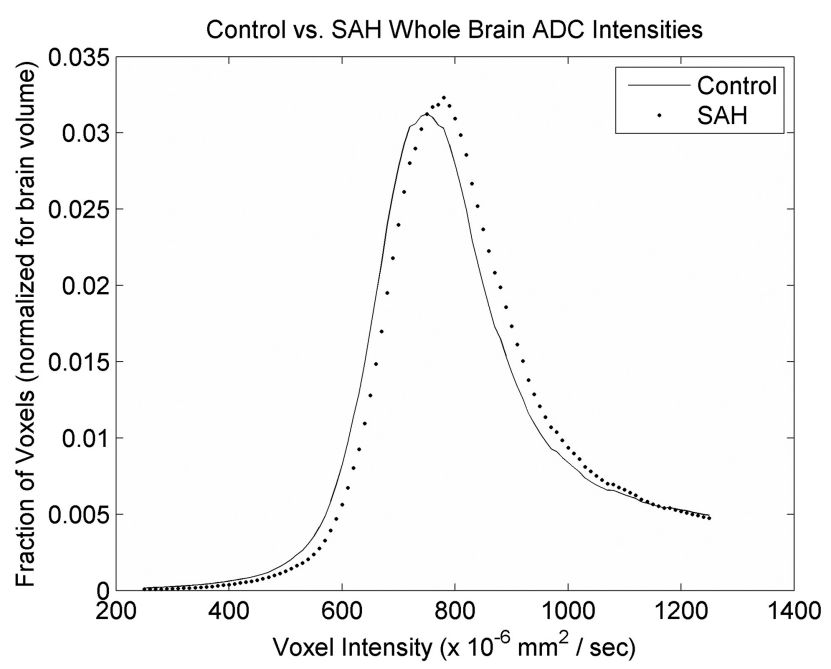

FIG 1. Composite histogram curves from all patients plotting fractions of voxels by voxel intensity in apparent diffusion coefficient maps of controls (line) and subjects with SAH (dots).

Table 2: Average median ADC values in ROIs in patients with SAH and controls ${ }^{\mathrm{a}}$

\begin{tabular}{lcccc}
\hline \multicolumn{1}{c}{ ROI } & $\begin{array}{c}\text { ADC }\left(\times 10^{-6} \mathbf{~ m m}^{2} / \mathbf{s}\right) \\
\text { Control }(\boldsymbol{n}=66)\end{array}$ & $\begin{array}{c}\text { ADC }\left(\times 10^{-6} \mathbf{m m}^{2} / \mathrm{s}\right) \\
\text { SAH }(\boldsymbol{n}=33)\end{array}$ & $\begin{array}{c}\text { P Value } \\
\text { Age-Adjusted } \\
\boldsymbol{P} \text { Value }\end{array}$ \\
\hline Cerebral gray matter & $803(36.2)$ & $826(37.7)$ & $.001^{\mathrm{b}}$ & .059 \\
Frontal & $802(65.2)$ & $823(66.4)$ & .137 & \\
Parietal & $820(48.0)$ & $843(53.5)$ & $.025^{\mathrm{b}}$ & \\
Occipital & $798(67.7)$ & $814(51.7)$ & $.042^{\mathrm{b}}$ & \\
Temporal & $791(43.6)$ & $822(60.6)$ & $.006^{\mathrm{b}}$ & \\
Cerebral white matter & $758(33.9)$ & $793(44.9)$ & $.001^{\mathrm{b}}$ & $.023^{\mathrm{b}}$ \\
Frontal & $735(53.0)$ & $768(55.8)$ & $.007^{\mathrm{b}}$ & \\
Parietal & $767(50.9)$ & $799(51.3)$ & $.007^{\mathrm{b}}$ & \\
Occipital & $764(36.8)$ & $795(47.7)$ & $.003^{\mathrm{b}}$ & \\
Temporal & $767(45.4)$ & $809(61.8)$ & $.003^{\mathrm{b}}$ & \\
White matter tracts & $739(33.5)$ & $797(59.3)$ & $<.001^{\mathrm{b}}$ & $<.001^{\mathrm{b}}$ \\
Genu & $761(45.2)$ & $816(69.1)$ & $<.001^{\mathrm{b}}$ & \\
Splenium & $736(45.6)$ & $789(91.4)$ & $<.001^{\mathrm{b}}$ & \\
Internal capsule & $719(53.2)$ & $785(96.4)$ & $<.001^{\mathrm{b}}$ & \\
Deep gray matter & $713(27.4)$ & $754(59.6)$ & $<.001^{\mathrm{b}}$ & $.016^{\mathrm{b}}$ \\
Thalamus & $730(45.1)$ & $777(86.8)$ & $.020^{\mathrm{b}}$ & \\
Caudate & $705(37.2)$ & $739(65.7)$ & $.002^{\mathrm{b}}$ & \\
Lentiform & $705(45.5)$ & $747(67.5)$ & $<.001^{\mathrm{b}}$ & \\
Hippocampus & $854(67.7)$ & $878(64.8)$ & .072 & \\
Midbrain & $795(93.5)$ & $813(47.4)$ & $.006^{\mathrm{b}}$ & \\
Pons & $706(50.6)$ & $756(54.6)$ & $<.001^{\mathrm{b}}$ & \\
Cerebellar gray matter & $756(48.9)$ & $796(67.7)$ & .001 & \\
Cerebellar white matter & $720(50.3)$ & $731(43.7)$ & .214 & \\
Summed ROls & $759(23.3)$ & $795(36.9)$ & $<.00^{\mathrm{b}}$ & $<.001^{\mathrm{b}}$ \\
\hline
\end{tabular}

${ }^{a}$ Values are reported as average median with SD.

b Statistical significance.
ADC values increased significantly with age in the combined cohort of controls and patients with SAH (Pearson correlation coefficient for median summed ROI ADC and age $=0.514, P<$ $.001)$, though this effect was primarily driven by patients with $\mathrm{SAH}$ (Pearson correlation coefficient $=0.602, P<.001$ ), while there was no correlation between age and ADC values among controls alone (Pearson correlation coefficient $=0.012, P=$ .924). Among patients with $\mathrm{SAH}, \mathrm{ADC}$ values increased as the modified Fisher score increased (median summed ROI modified Fisher score 1: $766 \times 10^{-6} \mathrm{~mm}^{2} / \mathrm{s}$; modified Fisher score 2: $754 \times$ $10^{-6} \mathrm{~mm}^{2} / \mathrm{s}$; modified Fisher score 3: $797 \times 10^{-6} \mathrm{~mm}^{2} / \mathrm{s}$; modified Fisher score 4: $813 \times 10^{-6} \mathrm{~mm}^{2} / \mathrm{s}$; Pearson correlation coefficient $=0.440, P=.010$ ). There was no correlation between ADC values and sex, elevated intracranial pressure, or external ventricular drainage.

In multivariable analysis, after we adjusted for age, wholebrain ADC values were still significantly higher in patients with SAH compared with controls $(P=.028)$. Similarly, after we adjusted for age, the average median ADC values remained higher in grouped ROIs for cerebral white matter $(P=.023)$, white matter tracts $(P<.001)$, deep gray matter $(P=.016)$, and summed ROIs $(P<.001$, Table 2$)$.

Evidence of cytotoxic edema was observed in 13 (39\%) patients with SAH. Cytotoxic edema was more prevalent in patients with SAH with more severe EBI (87.5\% of patients with HH $4-5$ versus $24.0 \%$ of patients with $\mathrm{HH} 1-3, P=.001)$. The median volume of ischemia was also higher in patients with $\mathrm{HH} 4-5$ than in those with $\mathrm{HH} 1-3(0.8 \mathrm{~mL}$; range, $0-88.8$ versus $0 \mathrm{~mL}$; range, $0-2.4 ; P=.001)$. The average median ADC value of ischemic lesions across all patients with $\mathrm{SAH}$ was $605 \times 10^{-6} \mathrm{~mm}^{2} / \mathrm{s}$. There was no significant difference in ischemic ADC values between patients with mild and severe EBI $\left(602 \times 10^{-6} \mathrm{~mm}^{2} / \mathrm{s}\right.$ for $\mathrm{HH} 1-3$ versus $619 \times 10^{-6} \mathrm{~mm}^{2} / \mathrm{s}$ for $\mathrm{HH} 4-5, P=$ $.721)$.

\section{DISCUSSION}

This study is one of the first to provide quantitative evidence of both early cytotoxic and vasogenic edema occurring within 72 hours of SAH compared with controls. On the basis of our previous work, ${ }^{8}$ we anticipated globally decreased $\mathrm{ADC}$ values in patients with $\mathrm{SAH}$ compared with controls because we hypothesized that the abrupt increase in intracranial pressure that follows aneurysm rupture would result in inadequate cerebral blood flow and subsequent ischemia, similar to cardiac arrest models. ${ }^{16}$ Indeed, animal studies demonstrate increased intracranial pressure followed by cerebral blood flow values below the infarction threshold immediately after SAH onset. ${ }^{17}$ Other mechanisms may concomitantly reduce cerebral blood flow, such as primary SAH-induced vasoconstriction, as shown in preclinical 


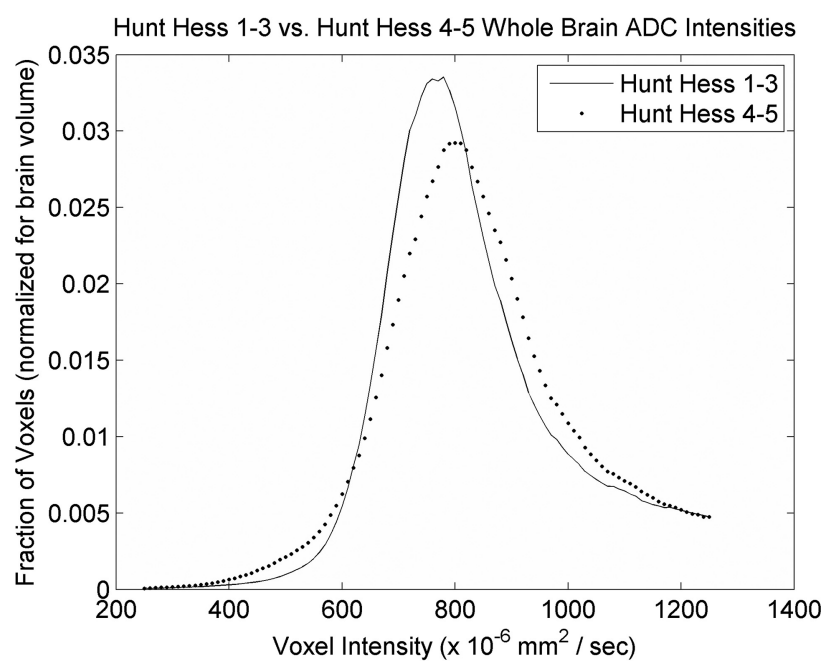

FIG 2. Composite histogram curves from all patients with SAH plotting the fraction of voxels by voxel intensity in apparent diffusion coefficient maps of patients with SAH with Hunt and Hess 1-3 (line) and Hunt and Hess $4-5$ (dots).

Table 3: Average median ADC values in ROls among patients with SAH with $\mathrm{HH} 1-3$ versus $4-5^{\text {a }}$

\begin{tabular}{|c|c|c|c|}
\hline ROI & $\begin{array}{c}\text { ADC } \\
\left(\times 10^{-6} \mathrm{~mm}^{2} / \mathrm{s}\right) \\
\mathrm{HH} 1-3(n=25)\end{array}$ & $\begin{array}{c}\text { ADC } \\
\left(\times 10^{-6} \mathrm{~mm}^{2} / \mathrm{s}\right) \\
\mathrm{HH} 4-5(n=8)\end{array}$ & $\begin{array}{c}P \\
\text { Value }\end{array}$ \\
\hline Cerebral gray matter & $823(25.9)$ & $833(64.1)$ & .159 \\
\hline Frontal & $821(60.9)$ & $831(85.9)$ & .785 \\
\hline Parietal & $844(55.4)$ & $843(50.6)$ & .753 \\
\hline Occipital & $813(41.0)$ & $819(80.3)$ & .556 \\
\hline Temporal & $816(52.1)$ & $840(83.5)$ & .172 \\
\hline Cerebral white matter & 787 (43.1) & $811(48.7)$ & .147 \\
\hline Frontal & $764(57.2)$ & $781(52.6)$ & .425 \\
\hline Parietal & $801(49.8)$ & $792(58.7)$ & 1.000 \\
\hline Occipital & $789(45.8)$ & $814(51.6)$ & .115 \\
\hline Temporal & $793.5(55.4)$ & $856(59.7)$ & $.014^{\mathrm{b}}$ \\
\hline White matter tracts & $796(58.4)$ & $798(66.1)$ & .916 \\
\hline Genu & $810(63.5)$ & $834(86.6)$ & .401 \\
\hline Splenium & 799 (79.1) & 758 (123.8) & .950 \\
\hline Internal capsule & 780 (103.7) & $801(71.9)^{\prime}$ & .401 \\
\hline Deep gray matter & $748(52.1)$ & $773(80.0)$ & .074 \\
\hline Thalamus & $763(81.4)$ & $820(94.7)$ & .097 \\
\hline Caudate & $737(57.8)$ & $743(90.8)$ & .130 \\
\hline Lentiform & $744(64.4)$ & $756(80.7)$ & .239 \\
\hline Hippocampus & $881(62.9)$ & $870(74.4)$ & 1.000 \\
\hline Midbrain & $811(43.2)$ & $818(61.9)$ & .378 \\
\hline Pons & $756(50.3)$ & $756(70.4)$ & .834 \\
\hline Cerebellar gray matter & 794 (75.5) & $800(36.8)$ & .324 \\
\hline Cerebellar white matter & $730(45.6)$ & $732(39.5)$ & .883 \\
\hline Summed ROls & $792(31.7)$ & $803(51.7)$ & .200 \\
\hline
\end{tabular}

a Values are reported as average median with SDs.

${ }^{\mathrm{b}}$ Statistical significance.

models using laser Doppler flow analysis. ${ }^{18}$ Hyperacute MR imaging in SAH endovascular perforation rat models has shown sharp ipsilateral declines in ADC within 2 minutes of SAH onset, followed by ADC value reductions in the contralateral cerebral cortex. ${ }^{19}$ While we did observe evidence of cytotoxic edema (reduced ADC values, which may represent ischemia) in $87.5 \%$ of patients with $\mathrm{SAH}$ with severe EBI, the volume of cytotoxic edema was too small to account for the clinical differences between those with severe-versus-mild EBI.

Instead, we noted diffusely increased ADC values in normal- appearing brain parenchyma in patients with SAH compared with controls and relatively higher ADC values in patients with SAH with more severe EBI. These data suggest the early presence of diffuse vasogenic edema, which is a direct consequence of abnormal blood-brain barrier permeability. Animal models of SAH demonstrate cerebral microvessel endothelial basal lamina disruption, acute loss of collagen $\mathrm{IV},{ }^{5}$ and increased microvessel permeability within minutes of SAH onset. ${ }^{20}$ Resultant blood-brain barrier breakdown and inflammation are evidenced by the escape of platelet aggregates and neutrophils into the brain parenchyma. ${ }^{6,21}$ Several other clinical studies have identified an increase in immunologic and inflammatory markers in patients with both unruptured intracranial aneurysms and subarachnoid hemorrhage. ${ }^{1,22,23}$ The association of higher ADC values with higher modified Fisher scores (and hence more intracranial hemorrhage) in our study suggests that the presence of blood products may play a role in the development of vasogenic edema.

Other MR imaging studies performed in patients with SAH corroborate our findings. In one study, the volume of DWI and FLAIR hyperintensities (assessed through manual ROI segmentation and documented within 48 hours of SAH ictus) was found to correlate with worse admission neurologic status and poor 3 -month functional outcomes. ${ }^{24}$ However, much of the FLAIR signal changes in this study were related to chronic injury in addition to the evolution of DWI positive for ischemic lesions and transependymal edema, possibly due to hydrocephalus. Our data do not demonstrate a significant association of intracranial pressure or external ventricular drain use and ADC values, suggesting that hydrocephalus and transependymal edema are not the causes of higher ADC measures. Additionally, elevated ADC values occurred in ROIs that are not immediately juxtaposed to the ventricles, where transependymal edema occurs.

In another analysis, 100 patients with aneurysmal SAH underwent DWI evaluation an average of 9 days after bleed onset. ${ }^{25}$ In this study, normal-appearing brain parenchyma had significantly higher ADC in the cerebral white matter and deep gray matter compared with healthy age-matched volunteers, while cerebral gray matter did not significantly differ between groups. Although evidence of radiographic vasospasm was not described, symptomatic vasospasm was observed in $14 \%$ of patients in this cohort. The authors also found that age was significantly associated with higher ADC values, but admission neurologic status (Hunt and Hess grades 1-2 versus 3-4, no subjects with Hunt and Hess 5 scores), treatment (surgical clipping versus endovascular coiling), and the severity of bleeding (modified Fisher grades 1-2 versus 3-4) were not significantly associated with ADC values. Limitations of this study include MRIs being performed during the vasospasm period (typically days 3-14 following aneurysm rupture) and signal change possibly representing pathology related to vasospasm rather than EBI due to aneurysm rupture.

In contrast to the above study, in which increases in ADC values were observed predominantly in the white matter and deep gray matter, we observed increases diffusely, including in the cortical gray matter, brain stem, and cerebellum. The timing of MR imaging in our study may account, in part, for this difference. Elevated ADC values have also been observed in other types of neurologic injury. In a study of traumatic brain injury, higher 
whole-brain peak ADC in normal-appearing parenchyma was significantly associated with worse Glasgow Coma Scores. ${ }^{26}$ While we found a trend toward higher ADC values in patients with SAH with worse admission neurologic status, our study was underpowered to detect a significant difference.

Although elevated ADC is typically due to increased extracellular water content, breakdown of the blood-brain barrier, and vasogenic edema, 1 additional possibility includes the pseudonormalization of ADC values during the subacute stages of ischemia. While there is some evidence of ADC heterogeneity early after acute ischemia, ${ }^{27}$ the overall time course of ischemic ADC changes involves 2 well-defined phases: an early reduction phase lasting between 96 and 144 hours, followed by a late elevation phase in which ADC values return to normal and even exceed normative values. ${ }^{28}$ Our study investigated an earlier time period of SAH, notably the acute phase lasting the first 72 hours. While we observed evidence of early brain ischemia in patients with $\mathrm{SAH}$, ischemic lesions were often punctate and randomly distributed. The low volumes of ischemia, the presence of elevated ADC in patients with SAH without evidence of acute ischemia, and a short timeframe from ictus to imaging are inconsistent with pseudonormalization and instead are strongly supportive of the occurrence of global vasogenic edema early after SAH.

Some limitations of our study should be mentioned. Because this was a retrospective study, there is a patient selection bias. MR imaging is not routinely performed at our institution following $\mathrm{SAH}$, and patients who underwent MR imaging may differ from those who did not. Furthermore, because MR imaging was performed as part of routine clinical practice, we were unable to account for possible subtle differences in patient movement or the effects of magnetic susceptibility, which may influence ADC values. Another limitation was that though the control group had normal MR imaging findings, these patients were not healthy controls but rather patients with a clinical symptom that prompted an MR imaging evaluation. It was necessary to select a control group that underwent imaging on the same inpatient MR imaging scanner to limit technical confounders. Hence, it was more expedient to use a patient group with normal-appearing MR imaging findings (based on neuroradiologist conventional assessment) rather than healthy controls who would be imaged on a different outpatient MR imaging scanner. We performed a 2:1 control to patients with SAH analysis to maximize our statistical power to detect a difference between control and SAH ADC values. Due to the low number of patients with SAH, we were unable to detect a significant association of ADC values with evidence of EBI or worse admission neurologic status. Although we did observe trends for higher ADC values in patients with $\mathrm{HH} 4-5$, a larger study would be necessary to confirm this effect. Finally, our patients with SAH were older than the controls. Previous studies have demonstrated increases in ADC values with age. However, even after controlling for age, differences in ADC values remained significant.

\section{CONCLUSIONS}

We observed evidence of early cytotoxic and vasogenic edema occurring within 72 hours of SAH ictus. Patients with SAH had significantly higher whole-brain and ROI ADC values than con- trols. Those with more EBI had significantly more cytotoxic edema and trended toward higher ADC values (more vasogenic edema) than those with better admission neurologic status. Both cytotoxic and vasogenic edema may be related to the mechanism of EBI following SAH or may represent biomarkers for the severity of EBI. Further study is necessary to determine whether either MR imaging marker is a significant predictor of functional outcome.

Disclosures: Jonathan M. Weimer-RELATED: Grant: American Heart Association, Comments: research supported in part by the American Heart Association Student Scholarship in Cerebrovascular Disease and Stroke.

\section{REFERENCES}

1. Frontera JA, Provencio JJ, Sehba FA, et al. The role of platelet activation and inflammation in early brain injury following subarachnoid hemorrhage. Neurocrit Care 2017;26:48-57 CrossRef Medline

2. Wartenberg KE, Schmidt JM, Claassen J, et al. Impact of medical complications on outcome after subarachnoid hemorrhage. Crit Care Med 2006;34:617-23, quiz 624 Medline

3. Grote E, Hassler W. The critical first minutes after subarachnoid hemorrhage. Neurosurgery 1988;22:654-61 CrossRef Medline

4. Sehba FA, Bederson JB. Mechanisms of acute brain injury after subarachnoid hemorrhage. Neurol Res 2006;28:381-98 CrossRef Medline

5. Sehba FA, Mostafa G, Friedrich V Jr, et al. Acute microvascular platelet aggregation after subarachnoid hemorrhage. J Neurosurg 2005; 102:1094-100 CrossRef Medline

6. Friedrich V, Flores R, Muller A, et al. Reduction of neutrophil activity decreases early microvascular injury after subarachnoid haemorrhage. J Neuroinflammation 2011;8:103 CrossRef Medline

7. Sehba FA, Friedrich V. Early micro vascular changes after subarachnoid hemorrhage. Acta Neurochir Suppl 2011;110(Pt 1):49-55 CrossRef Medline

8. Frontera JA, Ahmed W, Zach V, et al. Acute ischaemia after subarachnoid haemorrhage, relationship with early brain injury and impact on outcome: a prospective quantitative MRI study. J Neurol Neurosurg Psychiatry 2015;86:71-78 CrossRef Medline

9. Hadeishi H, Suzuki A, Yasui N, et al. Diffusion-weighted magnetic resonance imaging in patients with subarachnoid hemorrhage. Neurosurgery 2002;50:741-47; discussion 747-48 Medline

10. Sato K, Shimizu H, Fujimura M, et al. Acute-stage diffusionweighted magnetic resonance imaging for predicting outcome of poor-grade aneurysmal subarachnoid hemorrhage. J Cereb Blood Flow Metab 2010;30:1110-20 CrossRef Medline

11. Wartenberg KE, Sheth SJ, Michael Schmidt J, et al. Acute ischemic injury on diffusion-weighted magnetic resonance imaging after poor grade subarachnoid hemorrhage. Neurocrit Care 2011;14: 407-15 CrossRef Medline

12. Hunt WE, Hess RM. Surgical risk as related to time of intervention in the repair of intracranial aneurysms. J Neurosurg 1968;28:14-20 CrossRef Medline

13. Smith SM. Fast robust automated brain extraction. Hum Brain Mapp 2002;17:143-55 CrossRef Medline

14. Mlynash M, Campbell DM, Leproust EM, et al. Temporal and spatial profile of brain diffusion-weighted MRI after cardiac arrest. Stroke 2010;41:1665-72 CrossRef Medline

15. Frontera JA, Claassen J, Schmidt JM, et al. Prediction of symptomatic vasospasm after subarachnoid hemorrhage: the modified Fisher scale. Neurosurgery 2006;59:21-27; discussion 21-27 CrossRef Medline

16. Wijman CA, Mlynash M, Caulfield AF, et al. Prognostic value of brain diffusion-weighted imaging after cardiac arrest. Ann Neurol 2009;65:394-402 CrossRef Medline

17. Veelken JA, Laing RJC, Jakubowski J. The Sheffield model of sub- 
arachnoid hemorrhage in rats. Stroke 1995;26:1279-84; discussion 1284 CrossRef Medline

18. Bederson JB, Germano IM, Guarino L. Cortical blood flow and cerebral perfusion pressure in a new noncraniotomy model of subarachnoid hemorrhage in the rat. Stroke 1995;26:1086-91; discussion 1091-92 Medline

19. Busch E, Beaulieu C, de Crespigny A, et al. Diffusion MR imaging during acute subarachnoid hemorrhage in rats. Stroke 1998;29: 2155-61 CrossRef Medline

20. Friedrich V, Flores R, Muller A, et al. Luminal platelet aggregates in functional deficits in parenchymal vessels after subarachnoid hemorrhage. Brain Res 2010;1354:179-87 CrossRef Medline

21. Friedrich V, Flores R, Muller A, et al. Escape of intraluminal platelets into brain parenchyma after subarachnoid hemorrhage. Neuroscience 2010;165:968-75 CrossRef Medline

22. Hussain S, Barbarite E, Chaudhry NS, et al. Search for biomarkers of intracranial aneurysms: a systematic review. World Neurosurg 2015; 84:1473-83 CrossRef Medline

23. Chen S, Feng H, Sherchan $\mathrm{P}$, et al. Controversies and evolving new mechanisms in subarachnoid hemorrhage. Prog Neurobiol 2014; 115:64-91 CrossRef Medline

24. De Marchis GM, Filippi CG, Guo X, et al. Brain injury visible on early MRI after subarachnoid hemorrhage might predict neurological impairment and functional outcome. Neurocrit Care 2015;22: 74-81 CrossRef Medline
25. Liu Y, Soppi V, Mustonen T, et al. Subarachnoid hemorrhage in the subacute stage: elevated apparent diffusion coefficient in normalappearing brain tissue after treatment. Radiology 2007;242:518-25 CrossRef Medline

26. Shanmuganathan K, Gullapalli RP, Mirvis SE, et al. Whole-brain apparent diffusion coefficient in traumatic brain injury: correlation with Glasgow Coma Scale score. AJNR Am J Neuroradiol 2004;25: 539-44 Medline

27. Nagesh V, Welch KMA, Windham JP, et al. Time course of ADCw changes in ischemic stroke: beyond the human eye! Stroke 1998;29: 1778-82 Medline

28. Schlaug G, Siewert B, Benfield A, et al. Time course of the apparent diffusion coefficient (ADC) abnormality in human stroke. Neurology 1997;49:113-19 CrossRef Medline

29. van Swieten JC, Koudstaal PJ, Visser MC, et al. Interobserver agreement for the assessment of handicap in stroke patients. Stroke 1988; 19:604-07 CrossRef Medline

30. Hartley C, Cozens A, Mendelow AD, et al. The Apache II scoring system in neurosurgical patients: a comparison with simple Glasgow coma scoring. Br J Neurosurg 1995;9:179-87 CrossRef Medline

31. Hijdra A, Brouwers PJ, Vermeulen M, et al. Grading the amount of blood on computed tomograms after subarachnoid hemorrhage. Stroke 1990;21:1156-61 CrossRef Medline 